\title{
A STUDY OF PHOBIAS.*
}

\author{
By \\ HARRY A. PASKIND, Chicago.
}

SEmetology is frequently useful in the classification of morbid conditions. The prognosis and treatment of diseases in which phobias occur differ widely and it was thought worth while to determine whether phobias differ with the nosological position of the disorder in which they are found, and if these differences can be utilized in making a diagnosis. Since they occur both in the neuroses and in the psychoses it was considered that perhaps such a study might result in data that would be of aid in doubtful cases in the differentiation of the two. To this end the phobias occurring in 733 cases of psychoneurosis, 672 cases of manic-depressive psychosis, and 544 cases of dementia præcox from the private practice of Dr. Hugh T. Patrick were studied and the result of the study is the subject of this report.

\section{SOME VIEWS OF CAUSATION AND TREATMENT.}

There are, as is well known, different views as to the cause of phobias. According to Dejerine and Gauckler ${ }^{1}$ phobias in psychoneurotics occur as a result of the misinterpretation of various unpleasant or distressing sensations or experiences, which these patients so. often have. They stated that food phobias, for example, may occur as a result of attaching an erroneous signiticance to distressing sensations about the stomach, such as a feeling of pressure or heaviness. They also described phobias of heart disease as being caused by the misinterpretation of unpleasant sensations about the heart, such as fullness, tightness, or palpitation, and the phobia of impending insanity as due to attaching a wrong significance to such symptoms as headache, vertigo, disturbances of sleep, and disturbances of equilibrium. To take just one more example from these writers, they stated that from the fear of impending insanity the patient may develop the further fear of losing self-control and while in this state harm himself or perform a criminal deed. According to Dejerine and Gauckler, then, phobias in the psychoneuroses are understandable, logical, systematized; they have an adequate and obvious cause; and this cause is the misinterpretation of a peculiar or distressing physical sensation. Ballet ${ }^{2}$ held the same view ; among many instances he cited the case of a neurasthenic, suffering from rachialgia, who falsely interpreted this distress as indicating disease of the spinal cord, and developed the consequent phobia of disease of

* From the Department of Nervous and Mental Diseases, Northwestern University School of Medicine. Read at a meeting of the Central Neuropsychiatric Society, September 27, 1930. 
that part of the nervous system. Pollock ${ }^{3}$ described the occurrence of phobias in psychoneurotics as a result of the misinterpretation of physical sensations. Ross" described in neurasthenia the occurrence of fears for which the patient could give excellent reasons, such as that ' his head feels so queer that he must be going mad.' In other words, he placed on these fears the same interpretation as the above-mentioned writers, that such fears arose from the misinterpretation of various sensations. In compulsion neurosis Ross spoke of the occurrence of phobias for which the patient could give no reason.

Other writers, especially psychoanalysts or those psychoanalytically minded, have interpreted the causation of phobias quite differently. For Freud ${ }^{5}$ phobias do not have the simple, direct, logical, understandable systematized genesis of which the above writers give an account. He described two types of phobias. One type occurs in compulsion neurosis, and regarding them he wrote as follows: "In a predisposed person if there is no adaptation for conversion and still for the purpose of defence a separation of an unbearable idea from its affect is undertaken, the affect must then remain in the psychic sphere. The weakened idea remains apart from all association in consciousness, but its freed affect attaches itself to other not in themselves unbearable ideas, which on account of this 'false' connection become obsessions. This is in brief the psychological theory of the obsessions and phobias." Freud further stated that the phobias of anxiety neuroses (agoraphobia and its accessory forms) do not originate from repressed ideas, and that on psychological analysis they prove themselves not further reducible.

In the same way in which authors differ in their views as to the cause of phobias they also differ as to the method of the eradication of the latter. Thus Ballet" wrote: "The neurasthenic hypochondriac is amenable to reason; he readily lets himself be convinced by arguments when they are well put before him, and if it is sometimes difficult to cure his painful and unpleasant sensations by moral suasion, it is usually easy to dissipate for a time at least the erroneous and harrassing ideas (phobias) to which these sensations give rise." Dejerine and Gauckler ${ }^{1}$ and Pollock ${ }^{3}$ stated that these phobias are amenable to re-education and explanation. Those who hold that they are either not further reducible or are caused by suppressed ideas (Freud and his followers) have quite different views as to the method of eradication. They hold that mere explanation, persuasion, etc., are insufficient weapons for the purpose ; eradication according to their view is accomplished after a process of psychoanalysis-that is, an attempt to find the repressed ideas or emotions and bring them forth into consciousness.

The views of these various writers may be used as a method of approach in the study of the subject. Phobias may be examined from the standpoint of whether or not they have an obvious, understandable, logical systematized cause, and whether or not adequate explanation is sufficient to eradicate them. It was with these possible differences in mind that the present study was undertaken, and an attempt was made to determine whether these factors 
differ in the phobias that occur in the neuroses and in those that occur in the psychoses, and if these differences may be utilized as an aid in making a diagnosis.

\section{PHOBIAS IN THE PSYGHONEUROSES.}

In the 733 cases of psychoneurosis studied phobias occurred in 48 per cent.

The most common fear found in this series was the fear of becoming insane, which occurred in 151 instances. Its appearance was always due to the fact that the patient misinterpreted some sensation or experience as indicative of impending loss of mind. The most usual misinterpreted factor was the feeling of cephalic discomfort (pressure, heaviness, fullness, tightness, etc.) ; less commonly it was insomnia, restiveness, nervousness, and quick irritability. Still less frequently insanity occurred in the family of the patient, and the patient felt that the symptoms were surely the beginnings of the same trouble. Other rarer factors which the patient interpreted falsely as indicating impending loss of mind were worry, dizziness, head tremor, occasional feelings of confusion, bewilderment or daze, occasional spells of panic, masturbation, impotence, cessation of the menses, and tinnitus. In view of this it seems not unreasonable to believe that the fear of insanity in psychoneurotics is not a causeless, isolated, incomprehensible phenomenon; the patient has good reasons for the belief that insanity is impending, and this conviction is understandable ; it has an obvious and palpable cause, and that cause is the misinterpretation of a sensation or experience. We shall see in the further study of phobias in the psychoneuroses that this relationship will obtain.

The fear of physical disease was found in 141 psychoneurotics. The fear of heart disease was the most frequent. It was found in sixty cases, and had its genesis mostly in misinterpretation of an occasional attack of palpitation, or a sense of heaviness, discomfort or constriction about the heart, or in an occasional spell of giddiness or weakness. Sometimes the fear was of some abdominal disease, and an unpleasant abdominal sensation was the cause. Seventeen patients feared an oncoming stroke ; here, head pressure, or feelings of general weakness, or peculiar sensations in the arms and legs were the misinterpreted factors. More rarely there appeared fear of tuberculosis, goitre, epilepsy, general paresis, deafness, paralysis agitans, blindness, brain tumour, Bright's disease; but in each case the fear was caused by a misinterpretation of physical sensation such as a feeling of constriction about the chest or throat, trembling spells, pressure in the head, tinnitus, peculiar sensations in the abdomen, asthenopia, and frequent urination. Here too there were no incongruities, no incomprehensibilities, no imponderables; the occurrence of the phobia was predicated entirely on the misconstruction of a coexisting physical sensation.

The fear of impending death occurred in 90 cases, and in not a single instance was an obvious cause absent. Often a distressing experience was 
responsible, such as an attack of palpitation, a feeling of faintness or weakness, the feeling of pressure in the head increasing to unbearable proportions, a sense of constriction in the throat or precordium, or a spell of panic. In other instances this phobia owed its genesis to a pre-existing phobia of a fatal physical disease, most commonly heart disease, less often abdominal disease, or a stroke of apoplexy. Here we observe a phobia originating in another which itself was based on a peculiar sensation or experience ; we witness the elaboration of a phobia from a pre-existing phobia; this process, we shall see, is not at all rare in the psychoneuroses.

The fear of falling, collapsing, fainting or becoming unconscious was present in 58 instances, and in all the factor that gave rise to the fear was readily apparent. It was a distressing physical sensation such as palpitation of the heart, weakness, tremulousness, blurring of vision ; or it was based on other phobias such as the fear of heart disease or the fear of choking, these last having themselves been elaborated from distressing physical sensations.

The fear of being alone (claustrophobia) was found in 52 cases. The cause was always found in a pre-existing phobia. The phobia of sudden death was the most frequent cause, next came the fear of collapse, and the fear of becoming insane. It is quite understandable that an individual who is afraid that he may collapse, die, or go insane may also be afraid to be alone lest he should be without aid in these emergencies.

The fear of public places, streets, crowds, common carriers, poorly ventilated places was observed in 106 cases. Here too the cause was invariably a preexisting phobia, such as the fear of collapsing, fainting, dying, making a scene, choking amongst strangers, or being beyond the reach of quick aid in such circumstances.

The fear of killing or harming others was found in 14 psychoneurotics and was always based on the fear of impending loss of mind ; the same phobia was responsible for the 18 instances in which the individual feared that he might harm himself. The fear of high places was found in 16 instances, and it was always an elaboration of another such as that of becoming insane or uncontrolled, and jumping; or that looking down might oause a faint. The fear of sharp instruments or weapons was found in six ; in all it was conditioned by a fear of insanity or of losing control of one's self and of using weapons in such conditions with damaging effect. The fear of chaking was found in 21 cases of psychoneurosis, and was always based on a peculiar sensation, such as tightness or constriction in the throat or chest.

Some of the rarer phobias occurring in this series of psychoneurotics were the fear of leaving things undone based on difficulty of concentration; of sun and heat, based on a previous sunstroke; the fear of noise, based on noise aggravating the sensation in the head ; a fear of the condition being hopeless, in ten instances, due to the phobia of having an incurable physical disease.

A consideration of the above tends to show that phobias in the psycho. 
neuroses* are adequately caused, logical, understandable, systematized. They arise either from the misinterpretation of some physical sensation or experience or as elaborations from other phobias, which in turn developed out of the misconstruction of physical sensations. They are not isolated, incomprehensible phenomena, their genesis is simple and direct ; the object of the phobia is always a logical one. The cause is usually contemporaneous with the phobia or may just precede it.

After this criterion of a phobia occurring in the psychoneuroses-viz., that its cause is obvious.and easy to detect, adequate, logical, understandable, and systematized-was established, the phobias in other states were studied to see how they compare with this standard.

\section{PHOBIAS IN MANIG-DEPRESSIVE PSYGHOSIS.}

In the 672 cases of manic-depressive psychosis studied phobias occurred in 65 per cent.

In 17 instances there was found a fear of an unknown. The individual was afraid, but of what, could not be determined. Here is something different from that described above; here is a fear without a demonstrable cause and without an object-an incomprehensible fear. This is entirely foreign to anything found in the psychoneuroses; it is, it seems to me, the fear of a psychotic state.

The fear of having an incurable disease was found in 78 cases. It will be recalled that an identical phobia was found in ten cases of psychoneurosis, in which it was always an elaboration of the fear of having an incurable physical disease, which in turn was based on the misinterpretation of some peculiar physical sensation. But in the manic-depressive cases in which the same fear occurred, no such cause was in evidence. What gives rise to this fear in manic-depressives is hard to say ; perhaps it is darkness of mood, but whatever it is is not exactly clear, it is conjectural ; there is, in other words, something incomprehensible about it.

Among other illogical, incomprehensible, bizarre, vaguely conditioned fears found in the cases of manic-depressive psychosis may be mentioned that

* In 19 of the patients with psychoneurosis it was found that phobias had been present since childhood. In some the cause could not be ascertained because the incident responsible had long since been forgotten; in other cases it was found in some incident that took place very early in the patient's life, and recalled either by the patient or a relative as in the following instance :

An 18-year-old girl had had as far back as she could remember a fear of butterflies. She was brought to the consulting-room as, on a trip to Chicago the day before, she had been about to jump out of an automobile going at the rate of $\mathbf{4 0}$ miles per hour because a butterfly flew into the car. Inquiry from the mother elicited the fact that when the patient was 18 months old, long before she could remember, she was badly frightened by a butterfly alighting near her, while she was lying in a crib. From this and similar instances it seems reasonable to believe that phobias commencing very early in life and having no apparent rational basis are not illogical phobias; the circumstances that gave rise to them have been forgotten, but later the offending objects cause fear just the same. 
of never being able to fall asleep (three cases); fear of being unable to die (three cases); fear that a wet cuff will injure someone (one case); fear of contaminating others with disease (two cases) ; of putting harmful substances in edibles (four cases) ; of becoming blasphemous (one case) ; fear of its being the year 1921 (one case) ; fear of being injured by dirt in food (two cases) ; of not having turned off gas or locked doors (one case).

Logical, understandable fears were found in manic-depressive psychosis also. Thus in 152 instances the fear of impending insanity was present. The cause of this is somewhat different from what obtains in the psychoneuroses ; in the latter, one symptom is usually picked out as its cause, such as head pressure, insomnia, difficulty in concentration; in manic-depressive cases the stated origin does not appear to be so precise ; the patient appears to develop it from the general change that has come over him.

Fear of poverty for self and family and of business failure was found in 34 instances. In view of the fact that the patient usually realizes that he cannot attend to his business as well as formerly, this fear must be considered logical. It was not discovered in a single instance among the psychoneuroses. Claustrophobia was present in ten cases, and was always understandable since it was based on a pre-existing phobia such as that of impending death or insanity. Fear of harming others was found in two instances, originating in a pre-existing phobia of impending insanity. Fear of physical disease (15 cases) was based on the misconstruction of a physical sensation, and fear of impending death in ten instances arose in the same way.

\section{FEARS IN DEMENTIA PRÆGOX.}

Fears were found more rarely in dementia præaox than in the conditions discussed above. Among the 544 cases they were present in 54 . In only 17 of these was the phobia considered understandable; these were examples of the fear of impending insanity; here too it had its genesis in insomnia, a feeling of pressure in the head or difficulty in concentration. The remaining $3 i$ fears were without obvious or adequate cause. Fear of contaminating others with germs of disecse was noted in seven instances and led to excessive hand-washing or desire for separate utensils, towels, etc. A similar phobia was not found in a single case of psychoneurosis. The fear of death was present in six cases, the phobia of physical disease in five ; in neither group was there any obvious cause. The other apparently causeless fears noticed in this disorder were the fear of putting pins and glass in edibles, of batteries, of falling asleep, of noise, of being alone because the patient was ashamed of her appearance, of an unknown, of striking people in the street, of talking in a low voice, of not walking straight, of eating when in a sitting position, of eating oranges and apples, of not getting out of bed until a street car passed, and of a thing not being done right unless it was done twice. 


\section{TREATMENT .}

The treatment of patients with phobias also brings out some points of value in differential diagnosis. A phobia in dementia præcox or manicdepressive psychosis can rarely if ever be dispelled through reason. In the psychoneuroses the phobia may often be dispelled by reason alone or combined with normal behaviour despite the patient's sensations. In manic-depressive psychosis and in dementia præcox a fear cannot be counteracted by making the patient face it. The same fear recurring at intervals of months is usually indicative of a recurrent depression. In the psychoneuroses the whole picture is built around fear, in manic-depressive psychosis and in dementia præcox this symptom is only a small part of a largerclinical syndrome; there are many other complaints, but a psychoneurotic subject is concerned predominantly with his phobia.

\section{CONCLUSIONS.}

Phobias in the psychoneuroses have an obvious, adequate, understandable, logical, easily detected cause, and a clearly stated object. Such fears may also occur in the psychoses, but there illogical fears, fears having no. obvious or adequate cause and sometimes no object, are found. The detection of an illogical or inadequately caused fear is at once evidence that the condition in which it is found is a psychosis. Phobias occurring in the psychoneuroses are eradicable by reason, explanation, and by having the individual face the fear. Phobias in manic-depressive psychosis or dementia præcox, whether logical or illogical, are not eradicable by such procedures. It is thought that these factors may in doubtful cases help to clear up the point whether one is dealing with a neurosis or a psychosis.

\section{REFERENGES.}

${ }^{1}$ Dejerine, J., and Gadckler, E., The Psychoneuroses and their Treatment by Psychotherapy, translated by Smith Ely Jelliffe, 1913.

2 BALLeT, G., Neurasthenia, translated by P. Campbell Smith, 1908.

3 Pollock, L., J. The Medical Clinics of North America, 1928, ii, 31.

4 Ross, T. A., The Common Neuroses, 1924.

5 Freud, S., Selected Papers on Hysteria and other Psychoneuroses, translated by A. A. Brill, 1920. 